\title{
ALLOPURINOL IN THE PROPHYLAXIS OF URIC ACID STONES
}

\author{
BY \\ A. DE VRIES, M. FRANK, U. A. LIBERMAN, AND O. SPERLING \\ From the Metabolic Unit of the Department of Medicine D, and the Rogoff-Wellcome \\ Research Laboratories, Department of Experimental Biology, Tel-Aviv University Medical School, \\ Beilinson Hospital, Petah Tikva, Israel
}

Rational prophylaxis of uric acid lithiasis comprises two principles: increase of uric acid solubility in the urine achieved by raising the urinary $p \mathrm{H}$ (Peters and Van Slyke, 1946; Prien, 1955; Sperling and de Vries, 1964), and decrease of urinary uric acid (UUA) concentration, achieved by raising urine volume and decrease of UUA excretion. Whereas a rise in urinary $p \mathrm{H}$ is easily attained by oral alkalinization therapy (Atsmon, de Vries, and Frank, 1963; Kollwitz, 1964; Schmidt and Planz, 1965), two measures are available to decrease UUA concentration-high fluid intake and decrease in uric acid production, the latter having become recently feasible with the advent of the xanthine oxidase inhibitor, allopurinol (Wyngaarden, Rundles, Silberman, and Hunter, 1963). Satisfactory results have been reported in the literature in the prophylaxis of uric acid lithiasis by allopurinol in primary and secondary gout (Rundles, Silberman, Hitchings, and Elion, 1964; Yü and Gutman, 1964; Rundles, Metz, and Silberman, 1966b). In the present communication we wish to report on the treatment by allopurinol of non-gouty uric acid stone patients (Cases 1-7), and of one gouty patient with malignant uric acid lithiasis (Case 8).

The therapeutic results of allopurinol administration in the seven non-gouty uric acid stone patients (one female and six males) are presented in Table I. The age at which the urolithiasis first manifested itself ranged from 20 to 57 years. All patients had passed innumerable pure uric acid stones and "sand"; only two (Cases 1 and 6) had in addition voided a few stones also containing calcium salts. Two patients (Cases 5 and 6) had periods of urinary tract infection. All seven patients had good kidney function during the whole period of follow up, their creatinine clearances at the start of allopurinol treatment ranging from 105 to $130 \mathrm{ml} . / \mathrm{min}$. Alkalinization combined with high fluid intake had been satisfactory for prolonged periods in all but Case 6, who, did not apparently, persistently adhere to the regime.

Five patients did well on 300 to $600 \mathrm{mg}$. allopurinol for periods of 10 to 14 months, when repeat intravenous urography was normal in all. Allopurinol treatment had to be stopped early in Case 7 because of severe pruritus, and after 11 months in Case 6 because of leucopenia (total leucocyte count $2,200 / \mathrm{mm}^{3}$ ); in both patients these sideeffects occurred after the dose had been raised to $600 \mathrm{mg}$. per day. In Case $6 x$-ray evidence for a new stone was obtained after an attack of colic, 6 months after treatment with $300 \mathrm{mg}$. allopurinol per day.

Relevant laboratory data obtained during allo purinol treatment are given in Table II (overleaf). In the period of alkalinization, ranging from 3 to 9 years four patients showed hyperuricaemia $(9 \cdot 1,7 \cdot 7,7 \cdot 7 \overline{2}$. $7 \cdot 1 \mathrm{mg} . / 100 \mathrm{ml}$.), and three showed hyperuri? cosuria (1,140 to $1,600 \mathrm{mg}$./day). Interestingly, two of these hyperuricosuric patients (Cases 4 and 6) produced stones in the alkalinization period, but whether this stone formation was related to the hyperuricosuria cannot be decided, since both had also had at one time or another a very low urinary $p \mathrm{H}$, presumably related to inadequate regime.

During a short-lasting base-line period preceding allopurinol treatment, urinary $p \mathrm{H}$ reached low values in all patients and in all but one uric acid crystals appeared in the urine, in most in excessive amounts. Allopurinol decreased UUA excretion

*We regard 3 to $6.4 \mathrm{mg} . / 100 \mathrm{ml}$. as normal.

TABLE I

THERAPEUTIC RESULTS OF ALLOPURINOL IN SEVEN NON-GOUTY PATIENTS WITH URIC ACID STONES

\begin{tabular}{|c|c|c|c|c|c|c|c|c|}
\hline Case No. & Sex & \multicolumn{2}{|c|}{ Pre-treatment } & \multicolumn{2}{|c|}{$\begin{array}{c}\text { Alkalinization } \\
+\underset{+}{\text { High Fluid Intake }}\end{array}$} & \multicolumn{3}{|c|}{$\begin{array}{c}\text { Allopurinol } \\
+ \\
\text { High Fluid Intake }\end{array}$} \\
\hline $\begin{array}{l}1 \\
2 \\
3 \\
4 \\
5 \\
6 \\
7\end{array}$ & $\begin{array}{l}\mathbf{F} \\
\mathbf{M} \\
\mathbf{M} \\
\mathbf{M} \\
\mathbf{M} \\
\mathbf{M} \\
\mathbf{M}\end{array}$ & $\begin{array}{c}\text { Years } \\
1 \\
10 \\
6 \\
10 \\
1 \\
8 \\
4\end{array}$ & $\begin{array}{l}\text { Stones } \\
\times 100 \\
\times 100 \\
\times 100 \\
\times 10 \\
\times 100 \\
\times 100 \\
\times 100\end{array}$ & $\begin{array}{c}\text { Years } \\
8 \\
5 \\
5 \\
4 \\
3 \\
9 \\
3\end{array}$ & $\begin{array}{l}\text { Stones } \\
\overline{-} \\
\frac{1}{3} \\
-\end{array}$ & $\begin{array}{c}\text { Months } \\
10 \\
14 \\
14 \\
12 \\
14 \\
11 \\
3 / 4\end{array}$ & $\begin{array}{l}\text { Stones } \\
\text { - } \\
\overline{-} \\
\pm\end{array}$ & $\begin{array}{c}\text { Dose (mg./day) } \\
300 \\
300-400 \\
300-600 \\
300 \\
300 \\
300-600 \\
300-600\end{array}$ \\
\hline
\end{tabular}

* $X$-ray. 
TABLE II

URIC ACID VALUES, URINARY $p H$, AND URIC ACID CRYSTALS IN SEVEN NON-GOUTY PATIENTS WITH URIC ACID STONES

\begin{tabular}{|c|c|c|c|c|c|c|c|c|c|}
\hline \multirow{2}{*}{ Case No. } & \multicolumn{2}{|c|}{$\begin{array}{c}\text { Alkalinization } \\
+ \\
\text { High Fluid }\end{array}$} & \multicolumn{2}{|c|}{$\begin{array}{c}\text { High Fluid } \\
\text { Control up to } \\
6 \text { days }\end{array}$} & \multicolumn{5}{|c|}{$\begin{array}{c}\text { Allopurinol* } \\
\quad+ \\
\text { High Fluid }\end{array}$} \\
\hline & $\begin{array}{c}\text { Serum } \\
\text { (mg./100 ml.) }\end{array}$ & $\begin{array}{l}\text { Urine } \\
\text { (mg./day) }\end{array}$ & $\begin{array}{c}p \mathrm{H} \\
\text { lowest }\end{array}$ & Crystals & $\begin{array}{c}\text { Dose } \\
\text { (mg./day) }\end{array}$ & $\begin{array}{l}\text { Uric } \\
\text { Serum }\end{array}$ & $\begin{array}{c}\text { Urine } \\
\text { (mg./day) }\end{array}$ & $\underset{\text { lowest }}{p \mathrm{H}}$ & Crystals \\
\hline $\begin{array}{l}1 \\
2 \\
3 \\
4 \\
5 \\
6 \\
7\end{array}$ & $\begin{array}{l}3 \cdot 7-6 \cdot 2 \\
3 \cdot 5-7 \cdot 7 \\
3 \cdot 8-5 \cdot 9 \\
6 \cdot 4-9 \cdot 1 \\
4 \cdot 6-7 \cdot 7 \\
3 \cdot 2-7 \cdot 1 \\
3 \cdot 3-4 \cdot 3\end{array}$ & $\begin{array}{l}363-827 \\
516-844 \\
608-1,428 \\
547-1,140 \\
677-865 \\
373-1,600 \\
345-453\end{array}$ & $\begin{array}{l}5 \cdot 0 \\
5 \cdot 2 \\
5 \cdot 0 \\
4 \cdot 9 \\
4 \cdot 7 \\
4 \cdot 8 \\
5 \cdot 4\end{array}$ & $\begin{array}{c}+++ \\
+ \\
+ \\
+++ \\
+++ \\
+++ \\
+\end{array}$ & $\begin{array}{l}300 \\
300-400 \\
300-600 \\
300 \\
300 \\
300 \cdot 600 \\
300-600\end{array}$ & $\begin{array}{l}4 \cdot 7-3 \cdot 2 \\
5 \cdot 4-2 \cdot 5 \\
6 \cdot 1-3 \cdot 6 \\
5 \cdot 8-4 \cdot 3 \\
4 \cdot 6-3 \cdot 0 \\
4 \cdot 4-2 \cdot 9 \\
5 \cdot 3-2 \cdot 8\end{array}$ & $\begin{array}{r}567-227 \\
794-330 \\
1,035-347 \\
592-346 \\
626-271 \\
808-403 \\
647-340\end{array}$ & $\begin{array}{l}5 \cdot 0 \\
5 \cdot 2 \\
5 \cdot 0 \\
4 \cdot 9 \\
4 \cdot 8 \\
4 \cdot 8 \\
5 \cdot 4\end{array}$ & $\begin{array}{l}- \\
- \\
- \\
-\end{array}$ \\
\hline
\end{tabular}

* Data arranged chronologically.

in all patients, some requiring a daily dose of $600 \mathrm{mg}$. While receiving allopurinol, these patients, in all of whom alkalinization treatment had been discontinued, generally had a low urinary $p \mathrm{H}$, but their urine was now devoid of uric acid crystals. Presumably, as has been pointed out previously (Atsmon and others, 1963), the absence of uric acid crystals reflects a state of the urine prohibiting uric acid stone formation. In none of the patients did anaemia or hypoferraemia develop, nor did liver tests become disturbed.

Two cases illustrate well the excellent therapeutic effect of allopurinol in the prophylaxis of uric acid lithiasis.

A 54-year-old white male office worker (Case 5 in Tables I and II) was seen first on November 8, 1963, after suffering from recurrent left renal colic for $18 \stackrel{2}{2}$ months and passing hundreds of small reddish round on smooth stones, proved to be pure uric acid. The SUA is was $5.9 \mathrm{mg} . / 100 \mathrm{ml}$., UUA excretion $697 \mathrm{mg}$./day, creatinine clearance $130 \mathrm{ml} . / \mathrm{min} .$, and urinary $p \mathrm{H} 5 \cdot 4$; uric acid crystals were abundant. The intravenous 9 pyelogram was normal. There was no history of arthritis 8 and the family history was negative. Alkalinization $\vec{\theta}$ therapy was satisfactory but had to be discontinued after $\frac{0}{2}$ 2 years because of hypertension. Urinary $p \mathrm{H}$ fell to $4 \cdot 7 \rightarrow$ and massive uric acid crystalluria appeared. Allopurinol $Z$ $300 \mathrm{mg}$./day was started on January 31,1965 , and has now been given for 16 months; there is no crystalluria and no evidence of new stones (Fig. 1).

The second case is one of gout with malignant u acid lithiasis and excessive urinary uric acid ef cretion.
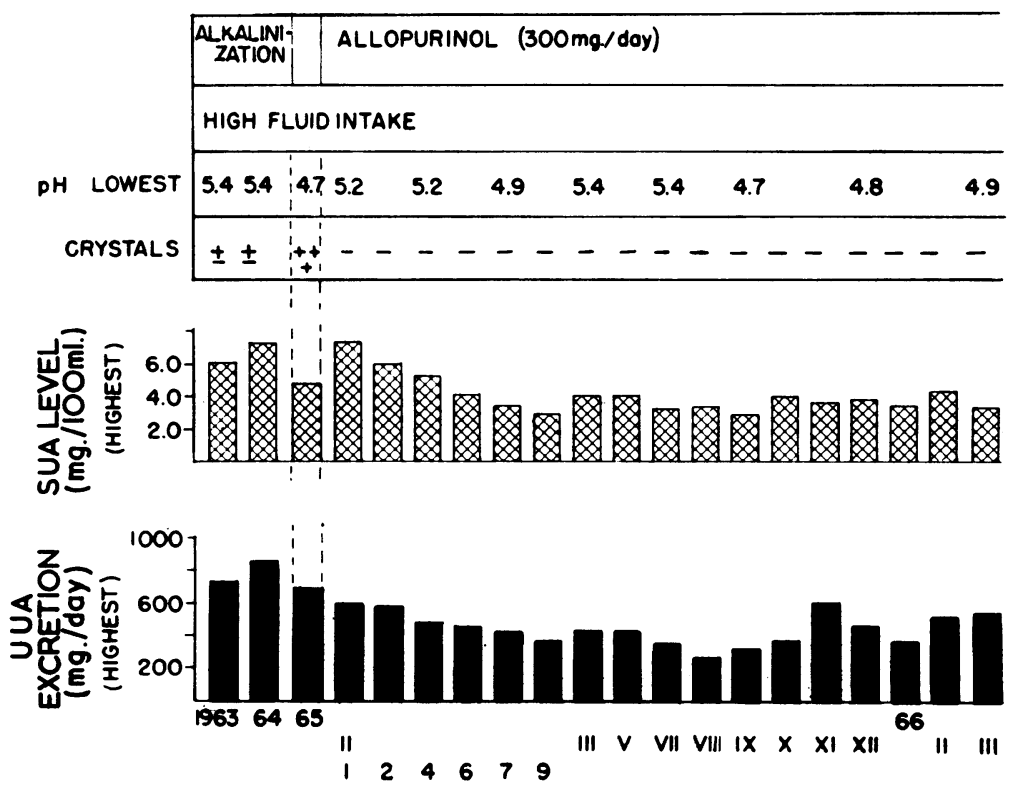

Fig. 1.-Allopurinol treatment in Case 5, a non-gouty patient with uric acid lithiasis. 
A 20-year-old Israeli-born agricultural worker (Case 8) was admitted to hospital on September 2, 1956, with anuria. He had suffered from recurrent renal colic for one year and had a typical attack of gouty arthritis. On admission he was anuric and azotaemic. After bilateral ureter catheterization, uric acid stones were surgically removed from the left ureter. He made a remarkable recovery and was treated by alkalinization, forced fluid intake, probenecid, and a low purine diet. On probenecid he had a very high UUA excretion, up to $4,200 \mathrm{mg}$./day. The SUA remained normal and there were no further gouty attacks. For the first 3 years of alkalinization therapy he did well, had no colic and did not pass stones or sand, and no uric acid crystals were found. Thereafter, however, uric acid crystalluria reappeared and in the period 1958 to 1965 he expelled a total of 34 stones, all of pure uric acid, except one which was mixed with calcium salt. The urinary $p \mathrm{H}$ was sometimes low. Since, presumably, this patient was not keeping to the prescribed regime, allopurinol $600 \mathrm{mg}$./day was started on May 14, 1965, alkalinization being continued. Probenecid was discontinued after 2 months. As seen in Fig. 2, UUA excretion dropped steeply and since then he has no colic, does not pass stones, and has no uric acid crystalluria. On April 19, 1966, allopurinol was discontinued for 7 days' evaluation of uric acid metabolism, and the SUA rose to a maximum of $15 \mathrm{mg}$./ $100 \mathrm{ml}$., and the UUA excretion to $3,400 \mathrm{mg}$./day. Allopurinol was then started again.

The excessive UUA excretion in this patient explains the "malignancy" of the uric acid lithiasis, and the relief obtained demonstrates the excellent theraputic effect of allopurinol.

Our observations show that allopurinol is indicated in the prophylaxis of uric acid lithiasis in patients in whom alkalinization therapy fails? (because of excessive UUA excretion or because of subjective difficulties in adhering to the regime) or is contraindicated (as in hypertension and heart $\frac{\bar{\sigma}}{\sigma}$ failure).

In considering whether allopurinol should be given $\overrightarrow{\widetilde{\Phi}}$ to all uric acid stone patients, including those who are non-gouty, even normouricosuric, and who respond's well to alkalinization, it must be kept in mind that in $\overrightarrow{0}$ most cases this prophylaxis must be for life (Atsmonand others, 1963). Since alkalinization combined with high fluid intake has proven a satisfactory means of long-term prophylaxis (Atsmon and others, 1963; Kollwitz, 1964), and since our experience or with continuous allopurinol therapy is as yet toow short to evaluate late side-effects, we feel that theo drug should be reserved for those in whom alkalini + zation is not successful. In view of the recurrence? of uric acid stones in some patients under allopurinole treatment (Rundles and others, 1966b), it seemso advisable to combine allopurinol with alkalinization.

\section{Summary}

Allopurinol was effective in the prophylaxis uric acid lithiasis in five out of seven non-goupy patients, and had to be discontinued in two because $f_{0}$ side-effects. An excellent result was obtained wisho allopurinol in a young gouty patient with malignant uric acid lithiasis and excessive urinary uric acido excretion.

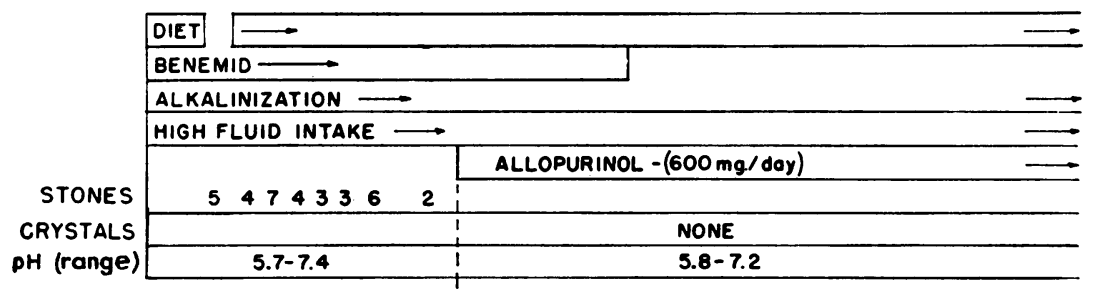
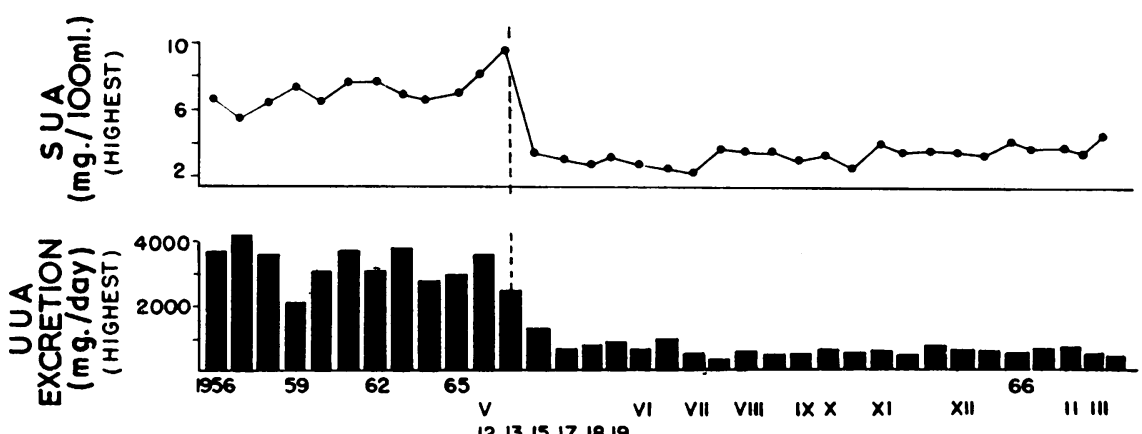

Fig. 2.-Allopurinol treatment in Case 8, a gouty patient with malignant uric acid lithiasis. 